\title{
Gender Determinants of Informal Labour Force Participation in Cameroon: The Role of Education
}

\author{
Badjo Ngongue Martial Annicet* Tachang Pius Ayekeh \\ PhD student, Faculty of Economics and Management Sciences - The University of Bamenda, \\ Cameroon, P.O Box 39, Bambili
}

\begin{abstract}
One of the most salient features of developing countries is the preponderance of the informal sector. This sector employs more than $90 \%$ of the labour in Cameroon. The main objective of this paper is to empirically examine gender factors that determine informal labour force participation in Cameroon with particular emphasis on the role of education. In order to achieve this objective, the paper used probit model on data collected from the second Cameroon Labour Force survey. Three models were estimated for the two gender sub samples and the total sample. Results from the data analysis reveal that education plays a very important role in explaining men and women decision to join the informal labour market. More precisely, at lower level of education, notably the primary level, women were more likely to join the informal sector of employment. At secondary level of education, women remained more likely to participate in the informal sector whereas the situation reverses for men. Another gender difference highlighted in the study is the fact that with the marital status: married men were more likely to join the informal employment unlike married women. Other factors significantly influencing informal Labour Force Participation include religion, age and urban zone of residence.
\end{abstract}

Keywords: Gender, informal labour force, education, probit,

JEL Classification: B30, B53, C11, C23, O10, O40

DOI: $10.7176 / \mathrm{JAAS} / 54-04$

Publication date: April $30^{\text {th }} 2019$

\section{Introduction}

Labour force participation is one of the key social indicators which determine the economic performance of a state and the well-being of its residents. As such, the labour force participation rate (LFPR) and the unemployment rate are of paramount concerns to state governments since living standards and consumption are so closely tied to work and earnings from employment (Lachowska and Woodbury, 2012). Growth in the labour force is therefore one of two key determinants of the nation's maximum sustainable rate of economic expansion (FRBSF, 2007).

For a long time, economists have studied gender inequality. They have found that increasing gender equality in education decreases fertility, increases human capital and increases economic growth (Dollar and Gatti, 1999; Klasen and Lamanna, 2009). There is growing empirical evidence to show that productive employment plays a key role in transmitting the benefits of economic growth into poverty reduction. In this regard, women employment plays an important role in reducing the dependency ratio and harnessing the potential labour force. Factors influencing demand for and supply of female labour can be different from those relevant for males, and therefore, it is important to devote particular attention to gender differences in factors affecting labour force participation. In developing economies, women employment plays an important role by complementing to household income, adding to the supply of labour for economic activities, and above all, by empowering women.

Women's capabilities have expanded dramatically across the world, thanks to progress in education, but the growth of women's opportunities still lags significantly behind those of their male counterparts (Chamlou et al, 2011). Most countries achieved the official MDG3 target of gender parity in primary and secondary school enrolment by 2005 . But efforts are still needed to create a more enabling environment for women to use their increased capabilities in the economy and society (World Bank, 2008).

Though 370.5 million women have joined the labour market in the past 20 years, they still account for just $39.8 \%$ of the global labour force. Moreover, the gap in participation rates of men and women has narrowed from 27.8 percentage points in 1992 to 26.0 percentage points in $2012(15+)$. Looking at just the 25 and older age group and abstracting from the effect of rising enrolment in education reveals a rise in the global female labour force participation rate, from $53.1 \%$ in 1992 to $54.2 \%$ in 2012 . At the same time, the gender gap for the adult working-age population 25 and older has fallen from 32.5 percentage points in 1992 to 29.5 percentage points in 2012 (ILO, 2013).

But even within regions where overall female labour force participation rates are low, there is considerable diversity. In South Asia for example, female participation rates range from around $20 \%$ in Pakistan to almost $80 \%$ in Nepal. Social and economic factors account for these differences. In Nepal women are less constrained by social norms and they work mostly in subsistence agriculture which is driven more by poverty than by choice. Rapid increase in women's participation in employment in Bangladesh is due to growth in the ready- 
made garment industry and a rise in livestock rearing (linked to access to micro-credit) (Rahman, 2013).

In many developing countries including Cameroon, serious effort and improvement have been made in educating girls. Since the pioneer work by Mincer (1962), there have been numerous studies on female labour participation. These studies highlight that women labour supply depends on economic and demographic characteristics such as female earnings, male earnings, non-earnings income, schooling, age, the number of children (Hill, 1983). Some of the studies have documented strong ties between women's work pattern and changes in their family status (Rindfuss et al. 1999). These results are based on the evidence that women who work for pay have fewer children than women who do not, and that mothers spend less time in paid employment than childless women as stated in Tsafack (2010).

Away from the foregoing survey of labour force participation in the world and sub-Saharan Africa, we now narrow our analysis to the situation of Cameroon. Employment in Cameroon, like elsewhere, provides for sustenance and enhances the quality of life. (Tingum, 2016). Over time, women have been putting in their share of economic and social effort, although immensely undermined (Mammen and Paxson, 2000). Their participation in labour force remains thin due to less employment and developmental opportunities for women, cultural and social barriers, discriminatory environment and low salaries. Moreover, their economic efforts remain imperceptible because the majority of women are working in informal sectors of labour market (Sarwar and Abbasi, 2013). In Cameroon, discriminatory attitudes are reflected in the labour market regulations. For example, in $2010,87 \%$ of women in the labour force were employed in vulnerable employment compared to $67 \%$ of men and $58 \%$ of women in the labour force were employed in agriculture compared to $49 \%$ of men (World Bank, 2015). These gender differences are associated with unequal access to resources such as time, income and social status (Zamo-Akono, 2009).

However, female labour force participation in the formal sector in Cameroon tends to show an overall increasing trend in recent times even though male labour force participation (MLFP) and total labour force participation are still lagging behind (TLFP). FLFP is spread to almost all ages and particularly from 20 to 45 years except for ages 12 to 19 years. The reason for this may be because they have attained higher education levels (In 2010, 65\% of women aged 15 and above were literate compared to $78 \%$ of men) which increase their access to opportunities to work in market activities and raises their market productivity compared with home production (World Bank, 2015).

An important characteristic of the Cameroonian labour market over the last few years has been the low participation of women in the labour force. The labour force participation of females in this country has dropped from 53.94\% in 2005 to 53.5\% in 2011 (Human Development Report, 2011). Though the labour force participation rate for male is greater than that of female, it is still far below other developing nations (World Bank, 2005).

The Labour Force Participation Rate (LFPR) has sensibly increased in Cameroon labour market (Tingum, 2016). Non-standard employment seems to represent a major form of labour market activity for a large number of working Cameroonians. The principal results of the surveys carried out in 2010 and 2015 on employment and the informal sector show that about 7 out of 10 persons are economically active (69\% in 2010, and $70 \%$ in 2014). In the urban area, 67.2 percent of men are economically active as against 52.2 percent of women. On the other hand, in rural areas, the difference between the activity rate of men and that of women is less pronounced. There is little difference between the rates for men and women owing to the high number of women working in rural areas. As a matter of fact, nearly 8 out of 10 men are active against 7 out of 10 women with the difference of 6.4 points.

Cameroonian informal sector has expanded dramatically over the past decades, especially, in urban areas. It is acquiring a predominant role, especially, in satisfying domestic demand and bringing together young people and women.

One of the salient features of the labour market in Cameroon is the distinctly lower participation rates of women compared with men in a predominantly informal sector. In 2014, while the participation rate of men (age 15+) was in the order of 76.9 percent, that for women within same age bracket was 64 percent (WDI, 2016). Empirical evidence shows that educational attainment is one of the major determinants of participation and employability for both men and women. Government efforts in improving female education have paved the way for their increased participation in the labour market, though their labour force participation rate is still low.

This paper, therefore, seeks to examine whether there exist gender differences in factors that determine informal labour force participation in Cameroon. Specifically, the paper places emphasis on educational attainment to assess the extent to which it affects male and female informal labour force participation in Cameroon.

The share of informality in the Cameroonian labour market has always been a topical issue and understanding the factors that account for gender participation in the informal labour markets is of prior importance in reducing gender gap and female discrimination in the labour market. This study will guide policymakers in designing measures to reduce the share of informality in the national labour market. 
The remainder of this paper is structured into three sections: sections 2 reviews some key concepts and literature in relation with the paper, sections 3 focuses on the methods and procedures adopted in carrying out the analysis and section four deals with the presentation and discussion of findings while the last section is devoted to conclusion and policy implications.

\section{Literature Review}

Though widely used, there is no universal and consensual definition of informal labour force participation (employment) among scholars. Most often the perspective taken by a researcher depends on the availability and accessibility of statistic information. The near consensual definition is from the International Labour Organisation's (ILO) (1972) which defines informal activities as "a way of doing things", characterised by: "ease of entry; reliance on indigenous resources; family ownership of enterprises; small scale of operation; labour intensive and adapted technology; skill acquired outside of the formal school system and unregulated and competitive markets".

The informal employment in informal enterprises (for small unregistered or unincorporated enterprises) includes employers, employees, account operators and unpaid family workers in informal enterprises. Sometimes known as undeclared, hidden or grey employment, informal employment can be broadly described as employment engaged in producing legal goods and services where one or more of the legal requirements associated with employment do not comply with OECD (2008). The informal economy itself is traditionally viewed as the deprived or disadvantaged sector employing unskilled, less educated, and urban migrants (Mazumdar, 1983). Thus, it plays a negative role in the economy by decreasing official output, reducing government tax revenue and constraining the growth of the private sector (Johnson et al., 1997; Lacko, 2000). Furthermore, the informal employees lack social security coverage and some or all of the protections provided by labour contracts.

Merrick (1976) defines informal sector workers by their lack of social security status. Pradhan and van Soest (1995) use a definition of fewer than six employees for Bolivia and Mexico, but Funkhouser (1997) undervalues fewer than five employees for an analysis of five Central American countries. The ILO (2003) definition is based on employees in small establishment, size of fewer than 5-10 employees (depending on the country). Under the guidelines of the statistical definition of informal employment established by the ICLS in 2003, informal employment covers casual jobs or jobs with limited short duration; jobs with hours of work or wages below a specified threshold; employment of persons in households; jobs where the employee's place of work is outside the premises of the employer's enterprise; or jobs for which labour regulations are not applied (Daza, 2005). Finally, Henley et al. (2009) indicate three definitions of informality: first, to the employment contract status; second, to the social security protection, and third, to the nature of the employment and the characteristics of the employer. In a nutshell, the way informality is defined in developing countries does matter and the conditional outcome of particular factors on the likelihood of informality varies greatly from one definition to another.

The Cameroonian literature on informal employment deviates from a traditional view of informality as evidence for labour market segmentation (Ningaye and Talla Fokam, 2014). Rather than seeing informal employment as a survival mechanism or last resort employment opportunity for low-productivity workers who are queuing until they find a better-paid job opportunity, new empirical studies argue that some informal workers "choose" informal employment. They do so since informal employment offers them a better financial return on their skills or experience (OECD, 2008). Additionally, informal sector offers a certain degree of flexibility in hours, place of work, and allows small businesses with entrepreneur ability to become successful. Maloney (1999) suggests that the informal sector in developing countries may be a desirable choice. Individuals working in the informal sector benefit from flexibility regarding working hours and in some cases the choice of work location. Women with children may especially value this aspect. Moreover, since wages in the informal sector are more likely to evade or avoid taxes, salaries in the informal sector may significantly exceeds post-tax salaries in the formal sector. This view suggests that workers may face an improved wage in the informal sector compared to the formal sector (Henley et al., 2009).

From the conceptual review above, it is evident that one of the key issues in analysing the informal sector of employment consists of defining it in the first place. Informal employment may refer to different realities depending on the researcher and the country. Informal labour force participation will be captured in this study following the Cameroonian definition by the National Institute of Statistics (NIS). As concerned education, it is the process of imparting knowledge in people. Whether formal or informal, education is the process through which human capital is achieved.

Doğrul (2012) applied a multinomial logit model and economic theory to household budget survey data to examine the determinants of formal and informal sector employment in the urban areas of Turkey. The analysis was carried out for men and women separately. The findings show that determinants of formal and informal employment in Turkey`s urban labour market vary by gender. Special emphasis was placed on the importance of 
sex (being male rather than female), marital status, household-headship and education variables, of which the first three present the disadvantaged position of women in the labour market. Most women work in the informal sector despite significant improvements in their education attainment. Overall results confirm that the urban labour market is heterogeneous and reveal how labour supply factors are valued in the labour market. They also indicate the existence of sex discrimination in the labour market.

Wamuthenya (2009) applied the multinomial logit on two cross-section labour-force survey data of two distinct points in time (1986 and 1998) to investigate the labour supply attributes associated with formal and informal sector employment during a phase of tremendous increase in women's LFPR (particularly of married women) and improved education attainment. Results revealed important similarities and dissimilarities between: the two sectors; the two sample periods; men and women; and married women separately. This confirms that Kenya's urban labour market is heterogeneous. Its findings also gave indications of sex discrimination in the labour market. Special importance was placed on age, education, sex, marital status, household-headship and spousal characteristics as concerns married women. Experience and education are highly valued in the formal sector although the outcome across time, gender and sector is mixed. A comparison of the two sample periods revealed a rising positive effect of education (particularly of secondary level and above) and its outstanding bearing on formal sector employment. Another observation is that low levels of education (primary level education or none) are important for sorting workers into informal sector employment. A further important finding is that education appears much more important for females than for males. However, the magnitude given to education in enhancing women's employment prospects in the formal sector is declining between the two periods while the opposite is true for men. Moreover, owing to a decline in their partner's earnings over time, women are more likely to enter the labour-force and seek informal sector employment.

Going by the Cameroonian literature, a study by Tingum (2016) used two models to analyse the determinants of female labour force participation (FLFP) and sectoral choices of females in the Cameroon labour market with data from the second Survey on Employment and the Informal Sector (EESI 2) conducted in 2010 in Cameroon. A probit regression was used to analyse the determinants of FLFP. Among the key determinants of FLFP were age and education. More so, females who live in urban areas, who are household heads, and who have tertiary education are more likely to participate in the labour market. Using a multinomial Logit model, the study analyses the sectoral choices for women given their participation in the labour market. The results also showed that females who have tertiary education, are Protestants, married, divorced and reside in urban areas are more likely to work in the industrial, commerce and service sectors.

Tchakounte and Mbam (2016) analysed the Labour Force Participation Rate (LFPR) of informal workers in Cameroon. They also estimated the effects of some determining factors on LFP decisions. These authors used data from the Cameroon National Institute of Statistics (CNIS), a three-wave panel obtained respectively in 2001, 2005 and 2010 for a sample of individuals in the labour market. Findings showed that the LFPR in informal sector increased substantially during latest years, particularly those of young workers. This rise in the LFPR is principally explained by the significant increase in the labour-market activity of the urban younger generation which has been improved by migration. Estimating a simple model of LFP with logistic methodology, they found that poverty, age and urbanization were significantly related with LFPR of informal labour market in Cameroon.

There are numerous studies on factors affecting labour force participation especially for women in the world. However little or nothing have been done in developing countries such as Cameroon. When these studies exist, more emphasis is placed on female labour force participation and studies looking at determinants of labour force participation sectoral choices are limited in number. The present study therefore seeks to add to the existing literature on labour force participation determinants and more especially on the sectoral choices determinants of LFP. In addition, this study has the ambition to examine the gender differences in factors affecting informal labour force participation in Cameroon.

\section{Methodology of the Study}

The study seeks to investigate factors affecting labour force participation of male and female in the informal sector. In order to achieve this objective three models of informal labour force participation are formulated changing only the dependent variable. The general form of the model using total informal labour force participation is as follows:

TILFP $=\beta_{0}+\beta_{1} E D U C+\beta_{2} M A R R I E D+\beta_{1} R E L I+\beta_{1} A G E+\beta_{1} A G E^{2}+\beta_{1} U R B A N+\varepsilon \ldots \ldots \ldots \ldots(1)$

Later on the total informal labour force participation is divided into two groups in order to account for gender differences. Equations 2 and 3 below are the male and female informal labour force participation:

$M I L F P=\beta_{0}+\beta_{1} E D U C+\beta_{2} M A R R I E D+\beta_{1} R E L I+\beta_{1} A G E+\beta_{1} A G E^{2}+\beta_{1} U R B A N+\varepsilon$

$F I L F P=\beta_{0}+\beta_{1} E D U C+\beta_{2} M A R R I E D+\beta_{1} R E L I+\beta_{1} A G E+\beta_{1} A G E^{2}+\beta_{1} U R B A N+\varepsilon$

Where:

TILFP, MILFP and FILFP: are total, male and female informal labour force participation respectively, 
measured as dichotomous variables that is 1 if the individual (male and / or female) belongs to the informal sector of labour market.

EDUC: level of education of the respondent including no education level (base category), primary education (category 1), secondary education (category 2) and tertiary education (category 3). Higher level of education may discourage informal labour force participation in favour of more formal jobs.

MARRIED: Marital Status is captured as a binary variable, that is, 1 if the respondent is married and 0 otherwise. Married people may be more likely to accept informal jobs as the view it as a coping strategy given the scarcity of employment opportunities in developing countries such as Cameroon.

RELI: Religion is captured by five categories (no faith = base category, Catholic = category 1, Protestant $=$ category 2 , Muslim = category 3 , other faiths = category 4 ).

AGE : Age of respondent is a continuous variable ranging from 15 to 64 years and age squared is included in the model to find out if there is a quadratic effect of age on informal labour force participation. As the worker grow older, the likelihood of joining the informal sector of employment increases given that informal jobs becomes a last resort option. However, at early stage, some graduate may join small firms operating in the informal sector upon graduation in order to gain experience and seek for more formal jobs later on. Therefore the sign of age is ambiguous.

URBAN: urban zone of residence is a binary variable that is 1 if the respondent is from the urban area and 0 otherwise. One of the most salient features of developing countries labour market is dualism with the few number of existing formal employment opportunities concentrated in big cities while the rural areas are exclusively or predominantly informal. We therefore expect a negative effect of urban residence on informal labour participation.

The three models specified above are estimated using the Probit estimation given the binary nature of our dependent variables. Regressing a limited dependents model (binary outcome model) using the Ordinary Least square technique can lead to spurious regression as the estimate may exceed 1 and fall below 0 which is not in accordance with the probability law. The Probit model is preferred to other binary choice models in accordance with early researchers (Tingum, 2016; Sackey, 2005) and because researchers tend to favour the assumption of normality of the Probit.

This study used the second Cameroon labour force survey (CLFS) by the National Institute of Statistics (NIS, 2010). This survey takes place after every five years, with the first one carried out in 2005 (EESI 1) and the second one in 2010 (EESI 2). This second survey (CLFS 2) which was undertaken from 16 May to 17 July 2010 enables us to appreciate the contribution of the informal sector to the economy, in terms of employment and added value. This second survey with a total of 34500 observations - of which 17,247 (50.25\%) are females - enables us to update the 2005 data and therefore to assess the evolution of non-agricultural informal sector.

\section{Presentation and Discussion of Findings}

As highlighted above, gender was accounted for by running sub samples probit analyses for male, female alongside the full sample analysis of factors affecting informal labour force participation in Cameroon. Table 1 below summarises the regression results of all the three models. 
Table 1: Factors affecting informal labour force participation in Cameroon

\begin{tabular}{|c|c|c|c|c|}
\hline Variables & Categories & DV: MILFP & DV: FILFP & DV: TILFP \\
\hline \multirow[t]{3}{*}{ Education } & Primary & $\begin{array}{c}0.1153 * * * \\
(0.0522) \\
\end{array}$ & $\begin{array}{c}0.2971 * * * \\
(0.0380) \\
\end{array}$ & $\begin{array}{c}0.3589 * * * \\
(0.0296) \\
\end{array}$ \\
\hline & Secondary & $\begin{array}{c}-0.2626 * * * \\
(0.0574)\end{array}$ & $\begin{array}{c}0.2011 * * * \\
(0.0425)\end{array}$ & $\begin{array}{c}0.1877 * * * \\
(0.0322)\end{array}$ \\
\hline & Tertiary & $\begin{array}{c}-0.9452 * * * \\
(0.0783)\end{array}$ & $\begin{array}{c}-0.3667 * * * \\
(0.0709)\end{array}$ & $\begin{array}{c}-0.3805^{* * *} \\
(0.0493)\end{array}$ \\
\hline Marital status & Married & $\begin{array}{c}0.2485 * * * \\
(0.0533)\end{array}$ & $\begin{array}{c}-0.1366^{* * *} \\
(0.0320)\end{array}$ & $\begin{array}{c}-0.1071 * * * \\
(0.0252)\end{array}$ \\
\hline \multirow[t]{4}{*}{ Religion } & Catholic & $\begin{array}{c}-0.2426 * * * \\
(0.0712)\end{array}$ & $\begin{array}{c}-0.3659 * * * \\
(0.0689)\end{array}$ & $\begin{array}{c}-0.3608 * * * \\
(0.0485)\end{array}$ \\
\hline & Protestants & $\begin{array}{c}-0.2706 * * * \\
(0.0725)\end{array}$ & $\begin{array}{c}-0.3559 * * * \\
(0.0696)\end{array}$ & $\begin{array}{c}-0.3633 * * * \\
(0.0492)\end{array}$ \\
\hline & Muslim & $\begin{array}{c}-0.2753 * * * \\
(0.0731)\end{array}$ & $\begin{array}{c}-0.9551^{* * *} \\
(0.0700)\end{array}$ & $\begin{array}{c}-0.6473 * * * \\
(0.0494)\end{array}$ \\
\hline & Other faiths & $\begin{array}{c}-0.3921 * * * \\
(0.0935)\end{array}$ & $\begin{array}{c}-0.5260^{* * *} \\
(0.0831)\end{array}$ & $\begin{array}{c}-0.5156^{* * * *} \\
(0.0607)\end{array}$ \\
\hline \multirow[t]{2}{*}{ Age } & Age & $\begin{array}{c}0.2450 * * * \\
(0.0041)\end{array}$ & $\begin{array}{c}0.1886^{* * * *} \\
(0.0035)\end{array}$ & $\begin{array}{c}0.2064 * * * \\
(0.0025)\end{array}$ \\
\hline & Age squared & $\begin{array}{c}-0.0027 * * * \\
(0.0000)\end{array}$ & $\begin{array}{c}-0.0020 * * * \\
(0.0000)\end{array}$ & $\begin{array}{c}-0.0022 * * * \\
(0.0000)\end{array}$ \\
\hline Residence & Urban & $\begin{array}{c}-0.4971 * * * \\
(0.0321)\end{array}$ & $\begin{array}{c}-0.6554 * * * \\
(0.0282)\end{array}$ & $\begin{array}{c}-0.5819 * * * \\
(0.0207)\end{array}$ \\
\hline \multicolumn{2}{|c|}{ Constance } & $\begin{array}{c}-2.8568 * * * \\
(0.0862)\end{array}$ & $\begin{array}{c}-2.2944 * * * \\
(0.0767)\end{array}$ & $\begin{array}{c}-2.5814^{* * *} \\
(0.0565)\end{array}$ \\
\hline \multicolumn{2}{|c|}{ Observations } & 15835 & 16748 & 32583 \\
\hline
\end{tabular}

Note: $* * *$ and $* * *$ represents significance at $10 \%, 5 \%$ and $1 \%$ respectively.

Source: The authors using CLFS, 2010

From the results presented above, it is clear that primary education increases the likelihood in favour of both male and female labour force participation in the informal sector. Put differently, men and women with a primary level of education are significantly more likely to join the informal job market. This result illustrates a practical situation on the ground where people with low level of education are confined to odd jobs which are usually from the informal sector. Even when employed in the formal economy they are not knowledgeable enough to request for a formal employment contract which can still be perceived as an informal job. It should be noted that the marginal effect for female informal labour force participation is greater than that of men implying that informality among women is more important. This finding conforms to that of Wamuthenya (2009) who found out that lower level of education (notably primary or no level of education) is capital in sorting workers into the informal sector of the labour market and more so, the effect of education is more important for female than male.

There is inconsistency in the effect of secondary level of education. Men with a secondary level of education were found to be less likely to join the informal employment in the informal sector of the economy than will women with this same level of education. Both results were found to be significant at $1 \%$. This outcome seem to suggest a potential bias against women in the formal sector of the economy which depicts a situation where women may need to go extra miles as concerned education to be able to compete with men in the formal labour market. Overall analysis however shows a positive effect of secondary education on the likelihood of informal labour force participation. This result is in line with the findings of Dogrul (2012) who claimed that most women were likely to join the informal sector of employment despite significant improvement in education. This result also reveals that there is heterogeneity in the informal labour market in Cameroon.

Furthermore, results from the probit regression above indicate that there is a negative effect of tertiary education on both male and female informal LFP which means that men and women with higher educational level are less likely to join the informal sector employment. Again the marginal effect in favour of men outweighs that of women confirming the heterogeneous nature of the informal labour market in Cameroon. It can also been observed that as education increases the probability of joining the informal sector falls though more rapidly among men which signifies that education plays a more vital role in escaping informal employment for men than for women.

Another significant difference in gender factor affecting informal labour force participation is observed with the marital status. Results from table 1 above reveal that married men are significantly more likely to join the 
informal sector of employment unlike married women who are less likely to participate in the informal labour market. This finding can be explained by cultural factors which makes the man the head of the family and as such, he provides for the needs of his family. Married men, therefore tend to be less patient in obtaining a formal employment since they view the informal sector as the fast solution in earning a living whereas married women tend to patiently choose to work in the formal sector where working hours and salaries are clearly specified. Again the decision to participate in labour market might not be the sole responsibility of a married woman as the husband may prefer formal employment especially in the public sector so as to be sure the wife will have enough time for children upbringing and household chores. This result contradicts with the findings of Wamuthenya (2009) who concluded that married women were more likely to join the informal labour market.

There is a negative relationship between religion and informal labour force participation as all the religious affiliations included in the analysis have a negative sign. This result is consistent across all the three models. However it should be noted that the effect is more noticeable for women than for men especially within the Muslim community. In fact, it is practically rare in Cameroon to find Muslim women working and when they do, they are usually confined within the formal sector like in administrative offices.

The coefficient of age is positive implying that as individuals grow older in Cameroon, they are more likely to participate in the informal labour market. The effect is more important for men as compared with women. This result can be justified by the fact that most men and women may find it difficult to join the formal labour market which is very narrow, and as they grow older they may turn to the informal sector which employs about $90 \%$ of workers in Cameroon in order to earn a living. However, the relative low marginal effect for women illustrates the ability of women to persevere longer in the formal job search market before joining the informal labour market. However, it should be noted that there is a threshold age after which the effect of age on the likelihood of informal LFP becomes negative. The maximum age after which age has a negative effect is estimated at about 90 years for men and 94 years for women.

As expected, both urban men and women are less likely to join the informal sector of employment as compared to their rural counterpart since all the coefficients of urban residence are negative. Moreover, the marginal effects are more important among women than men. This result is not surprising given that with urbanisation, the narrow formal private sector that operates alongside the public sector is concentrated in urban cities like Douala and Yaounde. Migration towards urban centres can also take its roots from the quest for more formal employment as opposed to informal employment especially in the agricultural sector in rural areas.

\section{Conclusion and Policy Implications}

Issues of labour market outcomes are and will remain topical over the years as employment remains one of the most important indicators of the health of an economy. This paper's objective was to identify factors that determine the decision to join the informal labour force and focus was placed on the role played by educational attainment. A probit regression was conducted on data from the second Cameroon Labour Force Survey for male and female subsamples alongside the full sample analysis. Results from the analyses highlight some consistencies on the effects of most of the variables retained for the analysis, notwithstanding some key differences in factors affecting male and female informal employment decisions.

Results show that education is a crucial factor in explaining both male and female to participate in the informal labour market. Precisely, at lower level of education, women were more likely to join the informal employment as compared to their male counterparts at similar level of education. Further, the study reveals that education reduces the likelihood in favour of female informal employment only at the tertiary level as against the secondary level for men. In addition the analysis indicates that there are gender differences in the effect of marital status on informal labour force participation as married men were found to more likely join the informal labour unlike married women. Factors like religion, age and urban residence were found to significantly affect informal labour force participation.

In terms of policy implications, the paper recommends that the Government of Cameroon should reinforce her policy of girl child education with the objective of encouraging the women in general to complete at least their secondary education. This will mean designing special educational packages that will entice the females to enrol and complete secondary and high school studies. Principally, government measures geared at promoting technical tertiary education will be an added advantage in reducing female discrimination towards the informal sector. Such measures may include adding female quotas in entrance examinations into higher institutes of learning in the technical fields.

\section{References}

Chamlou, N., S. Muzi, and H. Ahmed. (2011), Understanding the Determinants of Female Labor Force Participation in the Middle East and North Africa Region: The Role of Education and Social Norms in Amman. Working Paper No. 31, Alma Laurea Inter-University Consortium, Bologna, Italy.

Daza, J. L. (2005), Informal Economy, Undeclared Work and Labour Administration, Dialogue Paper No 9, 
International Labour Office, Geneva, pp. 1-67.

Doğrul, H. G. (2012), Determinants of formal and informal sector employment in the urban areas of turkey, International Journal of Social Sciences and Humanity Studies, Vol. 4, No 2, pp. 217-231.

Dollar, D., and Gatti, R. (1999). Gender Inequality, Income, and Growth: Are Good Times Good for Women? Policy Research Report on Gender Development, Working Paper No. 1, The World Bank, Washington, DC.

FRBSF, (2007) Federal Reserve Bank of San Fransisco Economic Letter. 2007-32, October 26, 2007

Funkhouser, E. (1997), Mobility and Labor Market Segmentation: The Urban Labour Market in El Salvador, Economic Development and Cultural Change, 46(1): 123-153.

Henley, A., Arabsheibani, G. R., Carneiro, F. G. (2009), On defining and measuring the Informal Sector: Evidence from Brazil, World Development, 37(5), 992-1003.

Hill, M. A. (1983). Female Labor Force Participation in Developing and Developed Countries. Review of Economic Perspectives 14 (4), 141-164.

Human Development Report (2011) "Sustainability and Equity: A Better Future for All"

International Conference of Labour Statisticians ILO (2003), Employment Situation and Trends in China, in Report of the 17 th Conference. ILO, Geneva.

International Labour Office (1972), Employment, Incomes and Equality: A Strategy for increasing Productive Employment in Kenya, Geneva: ILO.

ILO (2013): Key Indicators of the Labour Market. kilm@ilo.org. Accessed on December 10, 2013.

Johnson, S., Kaufmann, D., Shleifer, A., Goldman, M. I., and Weitzman, M. L. (1997), The Unofficial Economy in Transition, Brookings Papers on Economic Activity, (2), 159-239.

Klasen, S., and Lamanna, F. (2009). The Impact of Gender Inequality in Education and Employment on Economic Growth in Developing Countries: Updates and extensions. Feminist Economics (forthcoming).

Komon, J.-C. and Tchakounté N. M. (2008), Chômage et Emploi Informel au Cameroun, Revue d'Economie et Gestion Appliquée, 5, pp. 54-79.

Lachowska M. and Woodbury, L. (2012), "Labor Force Participation in Mississippi and Other Southern States". Employment Research Newsletter, Vol. 19, No. 2.

Lacko, M. (2000), Hidden Economy-an Unknown Quantity? Comparative Analysis of hidden Economies in Transition Countries, 1989-95, Economics of Transition, 8(1): 117-149.

Maloney, W. F. (1999), Does Informality imply Segmentation in Urban Labor Markets? Evidence from Sectoral Transitions in Mexico, World Bank Economic Review, 13(2): 275-302.

Mazumdar, D. (1983), Segmented Labor Markets in LDCs, American Economic Review, 73(2): 254-259.

Merrick, T. W. (1976), Employment and Earnings in the Informal Sector in Brazil: The Case of Belo Horizonte, Journal of Development Areas, 10(3): 337-354.

Mincer, J. (1962), Labour Force Participation of Married Women: a Study of Labour Supply. In: H. G. Lewis (ed.), Aspects of Labour Economics, pp. 63-101. Princeton, NJ: Princeton University Press.

Mammen, K., and Paxson, C. (2000). Women's Work and Economic Development. The Journal of Economic Perspectives 14 (4), 141-164.

Ningaye, P. and Talla Fokam, D. N. D. (2014), Labor Market Segmentation and Gender Inequality in Cameroon, International Journal of Business and Economics Research, 3(2): 89-98.

OECD (2008), OECD Employment Outlook, Declaring Work or staying Underground: Informal Employment in seven OECD Countries, Chapter 2, pp. 1-21.

Pradhan, M. and Van Soest, A. (1995), Formal and Informal Sector Employment in Urban Areas of Bolivia, Labour Economics, 2(3): 275-297.

Rahman, R. I. (2013). Female Labour Force Participation in Bangladesh: Trends, Drivers and Barriers. ILO AsiaPacific Working Paper, 2013

Rindfuss R.R., Cooksey E.C., and Sutterlin R.L. (1999), Young adult occupational achievement: Early expectations versus behavioural reality, Work and Occupation, 26, 220-263.

Sackey, H. A. (2005), Female Labour Force Participation in Ghana: the Effects of Education. AERC Research Paper, No. 150. Nairobi: African Economic Research Consortium.

Sarwar, F. and A. S. Abbasi (2013), An In-Depth Analysis of Women's Labor Force Participation in Pakistan, Middle-East Journal of Scientific Research 15 (2): 208-215.

Tchakounte, N. M. and Mbam, U. G. (2016), Labour Force Participation of Cameroonians in Informal Sector, International Journal of Innovation and Economic Development, Vol. 2, Issue 2, pp. 43-62

Tingum, E. N. (2016), Female Labor force participation and Sectoral Choices for females in Cameroonian Labor Market". International Journal of Innovation and Scientific Research, Vol. 21 No. 1, pp. 118-129

Tsafack, N. R (2010), Fertility Health and Female Labour Force Participation in Urban Cameroon, International Business Research, Vol. 3, No 2, pp. 136-156.

Wamuthenya, W. R. (2009), Gender Differences in the Determinants of Formal and Informal Sector 
Employment in the Urban Areas of Kenya across Time, Paper to be presented at the 18th IAFFE Conference in Boston, June 25-28, 2009.

WDI, (2016), Featuring the Sustainable Development Goals. Extracted from the full version of WDI 2016

World Bank, (2005), The World Bank Annual Report 2005: Year in Review, Volume 1. Washington, DC. (C) World Bank.

World Bank, (2008), The World Bank annual report 2008: Year in review. Washington, DC: World Bank.

World Bank, (2015), The World Bank Annual Report 2015. Washington, DC. (C) World Bank.

Zamo-Akono C. M. (2009), Female Labor Force Participation in Urban Cameroon: Do Children and Health Status Really Matter? Centre for the Study of African Economies, Oxford. 